\title{
Türkiye'de Sepet Kur Volatilitesinin GARCH Modellemesi: Asimetri Etkisi Yaklașımı
}

\author{
GARCH Modelling of Currency Basket Volatility in Turkey: Asymmetry \\ Impact Approach
}

Ayşegül Ladin SÜMER ${ }^{1}$

\begin{abstract}
Öz
Amaç: Volatilite, farklı makroekonomik değişkenler üzerindeki olası bir risk ölçüsü iken, finansal küreselleşmeden sonra döviz kuru volatilitesi için özel bir analiz süreci haline gelmiştir. Bu araştırmanın amacı, Türkiye'nin dış borç ve ticaretinde baskın olan dolar ve euro kurlarından oluşturulan sepet kur volatilitesinin incelenmesidir.

Tasarım/Yöntem: Sepet kur volatilitesi, 2001:M1-2020:M6 döneminde normal ve Student-t dağılımları altında GARCH, EGARCH, TGARCH ve PARCH modelleriyle analiz edilmiştir.

Bulgular: Söz konusu modellerin tahmin sonuçlarının karşılaştırmasına göre, sepet kur volatilitesinin belirlenmesinde en iyi model Student-t dağılımı altında PARCH (1,1)'dir. Öngörü performansı da yüksek olan Student-t dağılımı altındaki PARCH $(1,1)$ modelinin, sepet kur serisinin geleceğe yönelik projeksiyonlarında başarılı olacağı düşünülmektedir.

Sinırlılıklar: Sepet kur bileşeni olarak sadece dolar ve euronun değerlendirilmesi bu araştırmanın sınırlılığıdır.

Özgünlük/Değer: Sepet kur volatilitesinin modellenmesine ilişkin mevcut tek çalışmaya alternatif olarak literatüre katkı sağlaması araştırmanın özgünlüğünü oluşturmaktadır.

Anahtar Kelimeler: Sepet Kur, Volatilite, GARCH Modelleri,
\end{abstract} Asimetri Etkisi

\begin{abstract}
Purpose: While volatility is a possible measure of risk on different macroeconomic variables, it has become a special analysis process for exchange rate volatility after financial globalization The purpose of this research is to examine the volatility of the currency basket which formed from Turkey's external debt and trade in the dominant dollar and the euro currency.

Design/Methodology: Currency basket volatility was analyzed with GARCH, EGARCH, TGARCH and PARCH models under normal and Student-t distributions in the period 2001:M1-2020:M6.

Findings: According to the comparison of the estimation results of the said models, the best model in determining the basket exchange rate volatility is PARCH $(1,1)$ under Student-t distribution. It is thought that the PARCH $(1,1)$ model under the Student-t distribution, which also has a high predictive performance, will succeed in the future projections of the currency basket series.

Limitations: The limitation of this study is that only dollar and euro are used as currency basket components.

Originality/Value: Its contribution to the literature as an alternative to the only existing study on modeling currency basket volatility constitutes the originality of the study.

Keywords: Currency Basket, Volatility, GARCH Models, Asymmetry Impact
\end{abstract}

\footnotetext{
${ }^{1}$ Dr., ladins_83@ hotmail.com, ORCID: 0000-0001-6507-3954.
} 


\section{GíRiş}

Finansal gelişmeyi tamamlayıcı iki ana unsur olarak, finansal küreselleşme ve kriz, karşımıza çıkmaktadır. Finansal küreselleşme, uluslararası sermaye piyasalarının hareketliliği olarak tanımlanırken, gelişmiş ülkelerden gelişmekte olan ülkelere yönelik sermaye ihracatı, finansal varlık fiyat patlaması ve döviz kuru şokları şeklinde finansal krizle sonuçlanabilmektedir (Bordo \& Meissner, 2015: 2-3). Nitekim, kritik olan konu döviz kuru şoklarının ulusal para birimleri üzerinde oluşturduğu güçlü baskıdır (Gabaix \& Maggiori, 2014; Koop \& Korobolis, 2014). Politika yapıcıların döviz piyasasındaki volatiliteyi yani oynaklığı yakından takibi gerekmektedir. Bu sayede, elde edilen bilgiler dahilindeki öngörüler politika yapıcıların hareket alanını ve izleyecekleri yol haritasını belirlemektedir.

Diğer taraftan, volatilite ekonomi için bir risk ölçüsü olarak algılandığından, politika yapıcılar ve ekonomistler, volatilitenin ölçüm ve tahminini üzerinde durmuştur. Bu amaçla, Engle (1982) öncülüğünde, otoregresif koşullu değişen varyans (Autoregressive Conditional Heteroscedastic: ARCH), sonrasında Bollerslev (1986) taraından genelleştirilmiş koşullu değişen varyans (Generalized Autoregressive Conditional Heteroscedastic: GARCH) geliştirilmiş ve analizlerde yaygın olarak kullanılmıştır. Söz konusu modeller, yüksek dağılımlı volatilite kümelenmesine sahip özellikle finansal varlık ve döviz kuru gibi ekonomik değişkenlere uyarlanmaktadır. Döviz kuru volatilite kümelenmesine yönelik, gün içi verilerden aylık verilere kadar faklı sıklıklar kullanılarak yapılan analizlerin ilk örnekleri şunlardır: Andersen ve Bollerslev (1997) gün içi verileri, Engle ve Bollerslev (1986), Milhoj (1987), Hsieh (1989) günlük verileri kullanmıştır. Diebold (1988), haftalık verilerden, Domowitz ve Hakkio (1985) aylık verilerden yararlanmıştır. Baillie ve Bollerslev (1989) ise, günlük, haftalık ve aylık verilere dayalı çalışmayı tercih etmiştir.

Bu çalışmanın amacı da Türkiye'de sepet kur volatilitesini en iyi açıklayan GARCH modelini araştırmaktır. Buna göre, Türkiye ihracat, ithalat, dış borç ve hizmet gelirlerinde en fazla paya sahip olan dolar ve eurodan oluşturulan sepet kurdaki şokların etkisi asimetrik GARCH modelleriyle analiz edilecektir.

Bu kapsamda, çalışmanın takip eden bölümünde, teorik çerçevesine yer verilmiştir. Üçüncü bölümde konuyla ilgili ampirik literatür ele alınmıştır. Dördüncü bölümde, ampirik yönteme, beşinci bölümde ise veriye ilişkin bilgi verilmiştir. Altıncı bölümde bulgular değerlendirilmiş ve çalışma sonuç bölümüyle sonlandırılmıştır.

\section{TEORÍK CCERÇEVE}

Döviz kuru getirisi, sıfır koşullu ortalamaya sahip bir zaman serisi olarak varsayıldığında, $\left(Y_{t}\right)_{t=0}^{\infty}$ süreci şeklinde şöyle modellenir (Yang, 2006: 366-367):

$$
Y_{t}=\sigma_{t} \xi_{t}, \quad t=1,2, \ldots
$$

Denklem (1)'de, $\left\{\xi_{t}\right\}_{t=0}^{\infty} ; \mathrm{Y}_{0}$ 'dan bağımsız rastgele değişkenlerdir ve $E\left\{\xi_{t}\right\}=0, E\left\{\xi_{t}^{2}\right\}=1$, $E\left\{\xi_{t}{ }^{4}\right\}=m_{4}<+\infty$ iken $\left\{\sigma_{t}^{2}\right\}_{t=0}^{\infty}$ ise $\sigma_{t}^{2}=\operatorname{var}\left(Y_{t} \mid Y_{t-1}, Y_{t-2}, \ldots\right)$ olarak koşullu volatilite serisini ifade etmektedir.

Ampirik kanıtlar, $\sigma_{t}^{2}$ sonsuz sayıda geçmiş getiride $Y_{t-j}, j=1,2, \ldots$, azalan bir seyirde anlaşılmasını sağlamaktadır. Ampirik analizlerde, örneğin Bollerslev (1986) GARCH (p,q) modeli, geometrik olarak azalma oranıyla birlikte volatilite fonksiyonunun tüm geçmiş gözlemlere bağlı olmasina izin vermektedir.

En sık kullanılan GARCH $(1,1)$ modelinde, $\sigma_{t}^{2}$ yinelemeli olarak şöyle tanımlanır:

$$
\begin{aligned}
& \sigma_{t}^{2}=w+\beta Y_{t-1}^{2}+\alpha \sigma_{t-1}^{2}, \quad t=1,2, \ldots, 0<\alpha, \beta<\alpha+\beta<1 \\
& \quad \text { veya } \\
& \sigma_{t}^{2}=v\left(Y_{t-1}\right)+\alpha v\left(Y_{t-2}\right)+\alpha^{2} v\left(Y_{t-3}\right)+\cdots \alpha^{t-1} v\left(Y_{0}\right)
\end{aligned}
$$

Denklem (3)'te, $v(y)=\beta y^{2}+w$; Engle ve $\mathrm{Ng}$ (1993)'e göre modele dahil edilmesi gereken haber etkisi eğrisini temsil etmektedir. 
Ancak, $\sigma_{t}^{2}$ 'nin $\mathrm{Y}_{\mathrm{t}-1}, \mathrm{Y}_{\mathrm{t}-2} \ldots$ simetrik bağımlığı eleştirilmiş ve GARCH $(1,1)$ 'in asimetrik volatilite modeli şöyle ifade edilmiştir:

$$
\sigma_{t}^{2}=w+\beta\left(Y_{t-1}^{2}+\left.\eta Y_{t-1}^{2}\right|_{\left(Y_{t-1}<0\right)}+\alpha \sigma_{t-1}^{2}\right.
$$

Denklem (4)'te, $v(y)=\beta\left(y^{2}+\left.\eta y^{2}\right|_{(y<0)}\right)+w$ şeklindeki iyi ve kötü haber etki parametresi GARCH $(1,1)$ modeline dahil edilmiş ve asimetri etkisi de değerlendirilmiştir.

\section{LITERATÜR TARAMASI}

Ülkelerin benimsediği çeşitli döviz kuru rejimleri, uluslararası ticaret ve sermaye akışını, ekonomik refahı etkilerken, uygun para politikasının tasarlanmasında döviz kurundaki hareketlenmeleri öngörmek önemli rol oynamaktadır. Özellikle, esnek döviz kuru rejiminin ön plana çıkardığı volatilite, politika yapıcılar ve akademisyenler arasında tartışma ve analiz alanı haline gelmiştir. Döviz kuru volatilitesinin, risk değerlendirmesi ve yönetiminde önemli bir parametre olduğu düşünüldüğünde ise, finansal kararların alınmasında ARCH ve GARCH modelleri yol gösterici olmaktadır. Bu amaçla, farklı ülkelerin ekonomik dinamikleri göz önünde bulundurularak yapılan ve sonuçları değerlendirilen ampirik literatür özetlenmiştir.

Adeoye ve Atanda (2011), Nijerya'da dolar kuru volatilitesi şokları ve kalıcılığını GARCH $(1,1)$ modeliyle tespit ederken, Bala ve Asemota (2013), dolar, euro ve pound kuru volatilitesine ilişkin oluşturulan asimetrik GARCH $(1,1)$ modellerinin şokların varlığını reddettiğine dair önemli kanıtlar elde etmiş̧tir. Bosnjak vd. (2016) ise, Hırvatistan'da euro kuru için GARCH $(2,1)$, dolar kuru için GARCH $(1,1)$ modelinin en iyi modeller olduğunu belirlerken, negatif ve pozitif şokların, euro ve dolar kuru getirilerinin bir dönem sonraki dönem değişkenliğine işaret ettiğini gösteren ampirik bir kanıt bulamamıştır. Abdullah vd. (2017), Bangladeş için dolar kuru volatilite tahmininde en uygun modellerin GARCH $(1,1)$ olduğu sonucuna ulaşmıştır. Epaphra (2017), Tazmanya'da dolar kuru volatilitesi asimetri etkisini açıklayan en iyi modelin EGARCH $(1,1)$ olduğunu belirlemiş, bir önceki dönem dolar kuru dalgalanmasının mevcut dolar kuru dalgalanmasını etkilediğini belirtmiştir. May ve Farell (2017), Güney Afrika'da dolar, euro, yen ve sterlin kuru asimetrik GARCH (1,1) model sonuçlarının, kaldıraç etkisini kanıtladığını, negatif şokların pozitif şoklara kıyasla bir sonraki dönem daha yüksek dalgalanmaya yol açtığını açıklamıştır. Petrica ve Stancu (2017), Romanya'da EGARCH $(2,1)$ modelinin euro kuru getirilerinin tahmininde en iyi modeller olduğunu saptamıştır. Mohsin (2018), Pakistan'da ise, dolar kuru volatilitesinin açıklanmasında en iyi modelin EGARCH $(1,1)$ olduğunu tespit etmiştir. Son olarak, Ilu (2020), Nijerya'da dolar kuru ve hisse senedi endeksi volatilitesine ilişkin PARCH $(1,1)$ model sonuçlarının, kötü haberin aynı büyüklükteki iyi habere göre hisse senedi ve dolar kurunu daha çok etkilediğini göstermiştir.

Türkiye özelinde yapılan çalışmalarda ise, Güvenek ve Alptekin (2009), TGARCH $(1,1)$ modelinin reel efektif dolar kuru volatilitesini açıklayan en iyi model olduğunu gözlemlemiştir. Songül (2010), dolar ve euro getirileri için en başarılı modellerin EGARCH $(1,1)$ ve TGARCH $(1,1)$ olduğunu belirlemiştir. Söz konusu döviz kuru getirileri ile varyansları arasında anlamlı bir ilişki bulunamadığından, döviz piyasasındaki dinamiklerin riskten bağımsız olarak işlediği belirtilmiştir. Uysal ve Özşahin (2012), reel efektif kuru volatilitesinin giderilmesine ilişkin en uygun modelin GARCH $(1,1)$ modeli olduğunu tespit etmiştir. Emeç ve Özdemir (2014), dolar kurundaki volatilitenin ölçümünde TGARCH $(1,1)$ modelinin bașarılı olduğu sonucuna ulașmıștır. Parim (2014), dolar kuru volatilitesinin tahminine yönelik, en iyi model olarak TGARCH $(1,1)$ GARCH $(1,1)$ olarak belirlemiştir. Sağlam ve Başar (2016), dolar ve euro için en iyi modellerin piyasadaki iyi ve kötü haberlerin volatiliteye etkisini ölçmede EGARCH $(1,1)$ ve TGARCH $(1,1)$ olduğunu, sterlin volatilitesini açıklayan en iyi modelin ise $\operatorname{GARCH}(1,1)$ olduğunu görmüştür. İşçioğlu ve Gülay (2017), dolar kuru getirisinde $\operatorname{AR}(2)$-EGARCH $(2,2,2)$ modelinin istatistiksel olarak anlamlı asimetrik etkilerin varlığını doğruladığını saptamıştır. Bunun yanında, EGARCH ve TGARCH modellerinden elde edilen sonuçlar, negatif ve pozitif şokların etkisinin aynı olmadığını göstermiştir. Topaloğlu ve Ünal (2019), dolar ve euro kurları için en uygun modelin ARCH (1) olduğunu belirtmiştir. Ancak, Korur (2019), dolar kuru için TGARCH $(1,1)$, euro kuru için PARCH $(1,1)$ modeli en iyi tahmin modeli olduğu belirlerken, beklenenin aksine bu modellerde pozitif şokların volatiliteye daha çok yol açtı̆̆1 gözlemlenmiştir. Sekmen ve Ravanoğlu (2020) ise, dolar kurundaki volatilitenin 
belirlenmesinde en uygun modelin GARCH $(1,2)$ olduğunu, kriz gibi belirsizlik dönemlerinde yüksek dalgalanmanın birbirini takip ettiğini açıklamıştır.

Diğer taraftan, Güloğlu ve Akman (2007), nominal dolar kuru volatilitesi tahmininden elde edilen ARCH (2) ve GARCH $(1,1)$ modellerinin eksikliklerini gidermek için uygulanan SWARCH $(2,2)$ modelinin daha başarılı olduğunu belirtmiştir. SWARCH modelinden elde edilen sonuçlar, Türkiye ve dünyada yaşanan ekonomik ve siyasal olayların döviz kuru volatilitesini etkilediğini, volatilite dönemlerinin kalıcı olduğunu göstermiştir. Kaplan (2009), GARCH $(1,1)$ modelinden elde edilen ve dolar kurundaki volatilitenin imalat sanayi üretimde çalışanlar endeksi oranına ve imalat sanayi büyüme oranına olan etkisi VAR modelinde incelemiştir. VAR analizi sonucunda reel döviz kuru volatilitesinin imalat sanayi büyüme oranı üzerine olan etkisi istatistiksel olarak anlaml, imalat sanayi üretimde çalışanlar endeksi oranı üzerine etkisi ise istatiksel olarak tespit edilememiştir. Soytaş ve Ünal (2010), dolar, euro ve sterlin kurları volatilite öngörüsünün modellenmesinde, RMSE ölçütüne göre GARH $(1,1)$ grubu modellerin, MAE ölçütüne göre AR modellerinin başarılı olduğunu belirtmiştir. Volatilite öngörü modellerine dayalı olarak tahmin edilen VAR modellerinin performas karşılaştırmasında ise EWNA ve GARCH grubu modeller daha doğru sonuçlar vermiştir. Gür ve Ertuğrul (2012), dolar, euro ve poundun ihracattaki payına göre oluşturdukları sepet kur volatilitesi için, SWARCH $(2,1)$ modelinin öngörü performansının ampirik olarak karşılaştırılan ARCH (1) ve GARCH $(2,1)$ modellerine kıyasla daha başarılı olduğunu saptamıştır. Dursun (2015), reel dolar kuru belirsizliğinin belirlenmesinde GARCH $(1,1)$ modelinden elde ettiği sonuçları VEC analiziyle değerlendirmiştir. Analiz sonucunda, reel dolar kuru belirsizliği ve toplam yatırımlar arasında kısa dönemli nedensellik ilişkisine ulaşılmıştır. Kayral (2016) ise, dolar ve euro kuru volatilitesi için en uygun modelin TGARCH $(1,1)$ olduğu belirlemiş, döviz kuru getirilerinden volatilitelere doğru tek yönlü nedensellik tespit etmiştir.

Döviz kuru volatilitesi modellemesine ilişkin ayrıntılı olarak yer verilen ampirik literatürde, tek bir yabancı ülke parası ya da ayrı ayrı değerlendirilen yabancı ülke paralarının, ilgili döviz kurunu temsil ettiği görülmektedir. Sadece, Gür ve Ertuğrul (2012), dolar, euro ve poundan oluşturdukları sepet kur volatilitesine ilişkin modelleme yapmıştır. Dolayısıyla, Türkiye açısından uluslararası ticaret ve dış borçlanmasında en fazla paya sahip, dolar ve eurodan oluşan sepet kur değişkenin sadece bu çalışmada kullanılması, çalışmayı farklılaştırırken, güncel bir ampirik analiz olarak literatüre katkı sağlamaktadır.

Özetle, temel amacı, döviz kuru dalgalanmaları üzerindeki küçük ve büyük boyutlu varyansların zaman içindeki simetrik dağılımını tahmin etmek olan GARCH modeli, döviz kuru serilerindeki dalgalanmaların analizinde etkin hale gelmiştir. Diğer taraftan, GARCH modeli söz konusu dağılımların asimetrisini de dikkate almış, üstel GARCH (Exponential Generalized Autoregressive Conditional Heteroscedastic: EGARCH), eşikli GARCH (Threshold Generalized Autoregressive Conditional Heteroscedastic: TGARCH) ve üslü ARCH (Power Autoregressive Conditional Heteroscedastic: PARCH) modelleri geliştirilmiştir.

\section{YÖNTEM}

GARCH modeliyle, hata terimlerinin gecikmeli koşullu varyanslarını analize dahil ederken, doğrusal olmayan modellerin koşullu varyanslarının karakterize edilmesi ve asimetri etkisinin belirlenmesi mümkün değildir. Söz konusu eksikliği gidermek için EGARCH, TGARCH ve PARCH modelleri kullanılmaktadır.

\subsection{GARCH Modeli}

Geleneksel zaman serisi yöntemleri, hata terimlerinin $\left(\varepsilon_{t}\right)$ sabit varyanslı olma varsayımı altında çalışırken, Engle (1982) $\varepsilon_{t}^{\prime}$ nin $t$ dönemindeki varyansının geçmiş dönemlerdeki varyansıyla ardışık bağımlı (otokorelasyon) olduğunu gösteren ARCH modelini geliştirmiştir. Bu kapsamda, koşullu varyans, geçmiş örneklem varyanslarının doğrusal bir fonksiyonudur.

Yalnız, ARCH modeli analizlerinde koşullu varyans denklemlerinde nispeten uzun bir gecikme istenmektedir. Ayrıca, negatif varyans parametre tahminlerine ilişkin sorunlardan kaçınmak için sabit bir gecikme yapısı tercih edilmektedir. Bu nedenle, Bollerslev (1986), daha esnek bir 
gecikme yapısına izin veren GARCH modelini ileri sürmüştür. Diğer taraftan, $\varepsilon_{t}^{\prime}$ nin gecikmeli koşullu varyanslarınn da dahil edildiği GARCH modeli şöyle tanımlanır (Bollerslev, 1986: 308- 311):

$$
\sigma_{t}^{2}=w+\sum_{j=1}^{q} \beta_{J} \sigma_{t-j}^{2}+\sum_{i=1}^{p} \alpha_{i} \varepsilon_{t-i}^{2}
$$

Denklem (5)'te, $w$; sabit terimi, $\varepsilon_{t-i}^{2}$; ortalama denklemindeki kare artıkların gecikmesi olarak ölçülen ARCH terimini, $\sigma_{t-j}^{2}$; son dönem tahmini varyans GARCH terimini temsil etmektedir.

\subsubsection{EGARCH modeli}

Asimetri etkisinin irdelenmediği GARCH modelinde önemli olan, volatilitenin büyüklüğüdür. Nelson (1991), geliştirdiği EGARCH modeliyle, koşullu standart sapma işleminin ve asimetrik mutlak artıkların Box Cox güç dönüşümünü uygulamaktadır. Bu sayede, doğrusal olmayan modelleri doğrusallaştırarak asimetri etkisini incelemektedir. EGARCH modeli şöyledir (Nelson, 1991: 350):

$$
\log \left(\sigma_{t}^{2}\right)=w+\sum_{j=1}^{q} \beta_{J} \log \left(\sigma_{t-j}^{2}\right)+\sum_{i=1}^{p} \alpha_{i}\left|\frac{\varepsilon_{t-i}}{\sigma_{t-i}}\right|+\sum_{k=1}^{r} \gamma_{k}\left|\frac{\varepsilon_{t-k}}{\sigma_{t-k}}\right|
$$

Denklem (6)'da logaritmik koşullu varyans modeliyle, kaldıraç etkisinin kuadratik olmaktan ziyade üstel olduğu ve koşullu varyans tahminlerinin negatif olmadığı garanti edilmektedir. $\gamma_{i}<0$ olduğu takdirde kaldıraç etkilerinin varlığ 1 , hipotez tarafından test edilmektedir. $\gamma_{i} \neq 0$ ise etki asimetriktir.

\subsubsection{TGARCH modeli}

TGARCH modeli, eşikli koşullu varyansı dikkate almaktadır. Çünkü volatilitenin geçmiş değerlerinde eşik etkisinin olması doğaldır. Ayrıca, volatilitede doğrusal olmayan salınım davranışına izin vermek için negatif kısıtlamalar gevşetilmektedir. Bu kapsamda, farklı yönlerdeki modellemelerde bir işaret fonksiyonu olarak kullanılmaktadır. Bu bilgiler kapsamında TGARCH modeli şöyle ifade edilir (Rabemananjara \& Zakoina, 1993: 34):

$$
\sigma_{t}^{2}=w+\sum_{j=1}^{q} \beta_{J} \sigma_{t-j}^{2}+\sum_{i=1}^{p} \alpha_{i} \varepsilon_{t-i}^{2}+\sum_{k=1}^{r} \gamma_{k} \varepsilon_{t-k}^{2} I_{t-k}^{-}
$$

Denklem (7)'de, $\varepsilon_{t}=0$ ise $I_{t}^{-}=1$. Burada, $\varepsilon_{t-i}>0$, iyi haberler, $\varepsilon_{t-i}<0$ kötü olmak üzere, koşullu varyans üzerinde farklı etkiler mevcuttur. İyi haberlerin etkisi, $\alpha_{i}$ iken, kötü haberlerin etkisi $\alpha_{i}+\gamma_{i}$ şeklindedir. $\mathrm{Bu}$ çerçevede, $\gamma_{i}>0$ kötü haberlerin volatiliteyi artıracağına, $\gamma_{i} \neq 0$ ise haberlerin etkisinin asimetrik olduğuna işaret etmektedir.

\subsubsection{PARCH modeli}

Bollerslev (1986), GARCH modelinde koşullu varyansın gecikmeli artıklarının doğrusal işlevi ya da Taylor (1986) ve Schwert (1990), koşullu standart sapmanın doğrusal işlevi için genel bir model sınıfı oluşturmanın mümkün olduğunu belirtmiştir. Ding vd. (1993) tarafından asimetri parametresine yer verilerek geliştirilen PARCH modeli şöyledir (Ding vd., 1993: 98):

$$
\sigma_{t}^{\delta}=w+\sum_{j=1}^{q} \beta_{J} \sigma_{t-j}^{\delta}+\sum_{i=1}^{p} \alpha_{i}\left(\left|\varepsilon_{t-i}\right|-\gamma_{i} \varepsilon_{t-i}\right)^{\delta}
$$

Denklem (8)'de, $i=1, \ldots, r$ için $\delta>0,\left|\gamma_{i}\right| \leq 1 ; i>r$ ve $r \leq p$ için $\gamma_{i}=0$. Buna göre, $\gamma_{i}=0$ iken simetrik model setleri, $\gamma_{i} \neq 0$ iken asimetrik model setleri oluşturulmaktadır.

\section{VERI}

Sepet kurdaki volatiliteyi en iyi açıklayan asimetrik GARCH modelinin tespit edileceği bu çalışmada, (USD*0,5+EUR*0,5) şeklinde hesaplanan sepet kur $(S K)$ değeri kullanılmıştır. $\mathrm{Bu}$ amaçla, 2001:M1-2020:M6 dönemine ilişkin nominal döviz kuru serileri Türkiye Cumhuriyet Merkez 
Bankası (TCMB)-Elektronik Veri Dağıtım Sisteminden (EVDS) elde edilmiştir. Analize uygun hale getirmek için öncelikle logaritmik dönüşümü yapılan sepet kur $(L n S K)$ serisi, mevsimsel etkiler içermesi nedeniyle, Tramo/Seats yöntemiyle mevsimsellikten arındırılmıştır.

\section{BULGULAR}

Jarque-Bera (JB) test istatistiği, serilerin hata terimlerinin normal dağılıma sahip olup olmadığının belirlenmesinde yaygın olarak kullanılan bir yöntemdir. Normal bir dağılım için çarpıklık değerinin 0 , basıklık değerinin de 3 olması beklenir.

Şekil 1'de, LnSK serisi histogramı ve JB test istatistiği sonuçları sunulmuştur. Basıklık istatistiği 3'ü geçtiği için, dağılımın normal dağılıma göre tepesinin sivri olduğu ve bu nedenle dağılımın aşırı değerler içerebileceği anlamına gelir. Serilerin çarpıklık değerlerinin pozitif olması serilerin sağa çarpık olduğunu göstermektedir. JB olasılık değerleri ise, $\% 5$ anlamlılık düzeyinden küçük olduğu, $L n S K$ serisi normal dağılıma sahip değildir.

Şekil 1: LnSK Serisi Histogramı

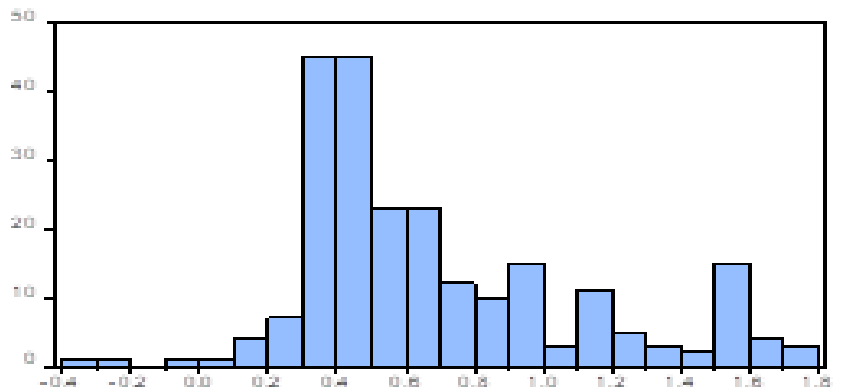

$\begin{array}{ll}\text { Ortalama } & 0.6845 \\ \text { Ortanca } & 0.5231 \\ \text { En Yüksek } & 1.7214 \\ \text { En Düş̈̈k } & -0.3729 \\ \text { Standart Sapma } & 0.414 \\ \text { Çarpıklık } & 0.8574 \\ \text { Basıklık } & 3.1016 \\ \text { Olasılık } & 0.0000\end{array}$

Tablo 1'de, Genişletilmiş Dickey Fuller (Augmented Dickey Fuller: ADF) ve Phillip-Perron (PP) testi birim kök testi sonuçlarına yer verilmiştir. LnSK serisi birinci farkında durağandır.

Tablo 1: ADF ve PP Birim Kök Testi Sonuçları

\begin{tabular}{|c|c|c|c|}
\hline Değişken & & ADF Test İstatistiği & PP Test İstatistiği \\
\hline \multirow{3}{*}{ LnSK } & Sabit & $0.511(2)$ & $-0.821(4)$ \\
\hline & & $-0.915(2)$ & $2.013(4)$ \\
\hline & Sabit ve Trend & {$[0.952]$} & [0.591] \\
\hline \multirow{3}{*}{$\Delta \operatorname{LnSK}$} & Sabit & $-11.869(1)$ & $-10.151(5)$ \\
\hline & Saboll & {$[0.000]$} & [0.000] \\
\hline & Sabit ve Trend & $\begin{array}{c}-11.877(1) \\
{[0.000]}\end{array}$ & $\begin{array}{c}-10.118(5) \\
{[0.000]}\end{array}$ \\
\hline
\end{tabular}

Not: LnSK; sepet kurdur. Köșeli parantez içindeki değerler, değişkenlerin p-olasılık değerlerini, parantez içindeki değerler ADF için Akaike bilgi kriteri (AIC) göre belirlenmiş optimum gecikme uzunluğunu, PP için Newey-West temelli Barnelt Kernel bant genişliğini, $\Delta$ serinin birinci farkının alındığını belirtmektedir. Serinin sabitte, düzey ve birinci farkındaki \%1, \%5 ve \%10 için kritik değerleri sırasıyla -3.459, $2.874,-2.573$ 'tür. Serinin sabit ve trendde, düzey ve birinci farkındaki \%1, \%5 ve \%10 için kritik değerleri sırasıyla $-3.998,-3.429$, 3.138 'dir.

ADF ve PP birim kök testlerinin aksine sıfır hipotezi serinin durağan olduğu, karşı hipotezi ise durağan olmadığ 1 Kwiatkowski-Phillips-Schmidt-Shin (KPSS) birim kök testi, bir anlamda bu testlerin sağlamas1 niteliğindedir. Tablo 2'deki KPSS birim kök testi sonuçlarından görüleceği üzere, LnSK serisi birinci farkında durağandır.

Tablo 2: KPSS Birim Kök Testi Sonuçlanı

\begin{tabular}{llcccc}
\hline \multirow{2}{*}{ Değiş̧ken } & \multicolumn{1}{c}{$\begin{array}{c}\text { KPSS Test } \\
\text { İstatistiği }\end{array}$} & $\mathbf{\% 1}$ & \multicolumn{2}{c}{ Kritik Değerler } \\
$\mathbf{2 5}$ & $\mathbf{\% 1 0}$ \\
\hline \multirow{2}{*}{$\boldsymbol{L n S K}$} & Sabit & $1.8003(11)$ & 0.7390 & 0.4630 & 0.3470 \\
\cline { 2 - 6 } & Sabit ve Trend & $0.4218(11)$ & 0.2160 & 0.1460 & 0.1190 \\
\hline \multirow{2}{*}{$\boldsymbol{L n S K}$} & Sabit & $0.1799(3)$ & 0.7390 & 0.4630 & 0.3470 \\
\cline { 2 - 6 } & Sabit ve Trend & $0.1801(3)^{* * *}$ & 0.2160 & 0.1460 & 0.1190 \\
\hline
\end{tabular}

Not: LnSK; sepet kurdur. Parantez içindeki değerler NeweyWest temelli Barnelt Kernel bant genișliğini ifade etmektedir. ***, \%1 anlamlılık düzeyinde serilerin durağanlığını ifade etmektedir. $\Delta$ serinin birinci farkının alındığını belirtmektedir. 
Durağan ve durağan olmayan $L n S K$ serisi arasındaki farkın daha iyi anlaşılabilmesi için Şekil 2'de durağanlık grafiklerine yer verilmiştir. $L n S K$ serisi düzeyde, yukarı yönlü bir trend izlerken, birinci farkı alındıktan sonra belirli bir değer etrafında hareket etmektedir.

Şekil 2: LnSK Serisi Durağanlık Grafikleri

Düzeyde Durağan Olmayan Seri

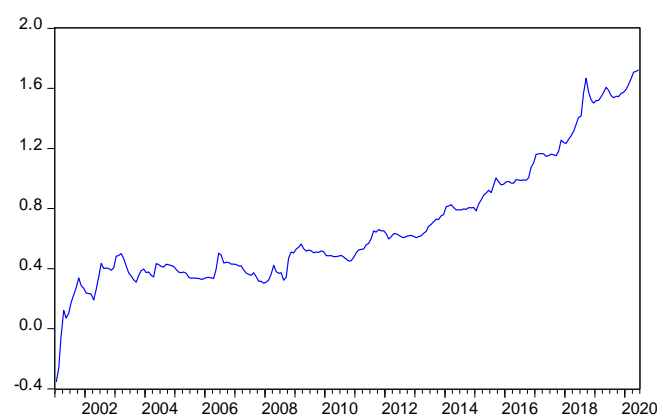

Birinci Farkında Durağan Olan Seri

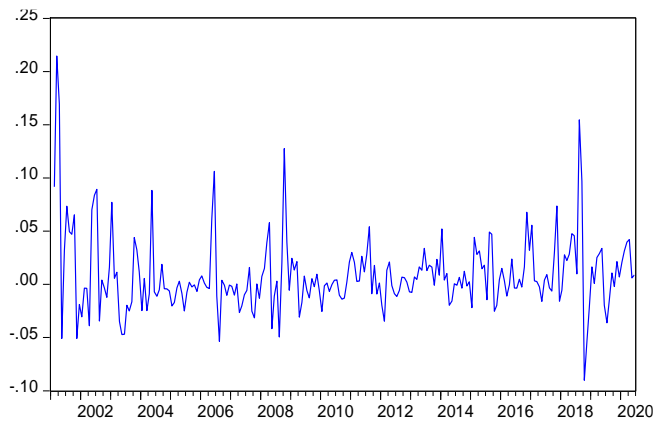

Diğer taraftan, yapısal kırılmaları değerlendirmeyen birim kök testlerinin hatalı sonuçlara yol açabileceği varsayımına dayalı olarak yapısal kırılmalı birim kök testleri geliştirilmiştir. Bu testler; bir ya da iki yapisal kırılmaya izin veren Perron (1989), Zivot ve Andrews (1992), Lumsdaine ve Papell (1997), Perron (1997), Lee ve Strazicich (2003) testleridir. Kapetanios (2005) birim kök testi ise beş yapısal kırılmaya kadar izin verirken, yapısal kırılma tarihleri içsel olarak değerlendirilmektedir. $\mathrm{Bu}$ amaçla, Kapetanios birim kök testinden yararlanılmış ve test sonuçları Tablo 3 'te sunulmuştur. LnSK serisi birinci farkında durağandır.

Tablo 3: Kapetanios Birim Kök Testi Sonuçları

\begin{tabular}{|c|c|c|c|c|c|c|}
\hline \multirow{2}{*}{ Değişken } & \multirow{2}{*}{ Modeller } & \multirow{2}{*}{$\tau$ - istatistiği } & \multicolumn{3}{|c|}{ Kritik Değerler } & \multirow{2}{*}{$\begin{array}{c}\text { Yapısal Kırılma } \\
\text { Tarihi }\end{array}$} \\
\hline & & & $\% 1$ & $\% 5$ & $\% 10$ & \\
\hline \multirow{4}{*}{ LnSK } & Model 1 & -1.920 & -5.338 & -4.930 & -4.661 & 2002M07 \\
\hline & Model 2 & -3.916 & -5.014 & -4.495 & -4.414 & 2012M10 \\
\hline & Model 3 & -3.834 & -5.704 & -5.081 & -4.820 & 2012M09 \\
\hline & Model 4 & -0.771 & -4.899 & -4.354 & -4.078 & 2002M07 \\
\hline \multirow{4}{*}{$\triangle L n S K$} & Model 1 & $-6.630 * * *$ & -5.338 & -4.930 & -4.661 & 2002M06 \\
\hline & Model 2 & $-6.733 * * *$ & -5.014 & -4.495 & -4.414 & 2002M05 \\
\hline & Model 3 & $-6.702 * * *$ & -5.704 & -5.081 & -4.820 & 2003M06 \\
\hline & Model 4 & -5.546 & -4.899 & -4.354 & -4.078 & 2002M06 \\
\hline
\end{tabular}

Not: $\operatorname{LnSK}$; sepet kurdur. ***, \%1 anlamlılık düzeyinde serilerin durağanlığını ifade etmektedir. Kritik değerler, bootstrap yardımıyla 1000 yinelemeyle elde edilmiştir. $\Delta$ serinin birinci farkının alındığını belirtir.

Test, Kasım 2000 ve Şubat 2001 krizleri ile 2008 küresel krizinin ülkemiz döviz piyasasındaki olumsuz etkilerini hafifletmek amacıyla döviz yönetiminin esnekliğini, iç ve dış şoklara karşı dayanıklılığını artırmasına yönelik uygulanan para politikası stratejilerini başarılı bir şekilde tespit etmiş, analize dahil edilmiştir. Öncelikle, Kasım 2000 ve Şubat 2001 krizlerinin ardından, sabit veya öngörülebilir döviz kuru rejimi yerine, döviz kurunun ekonominin dinamiklerindeki değişimlere göre piyasada oluşmasına yönelik dalgalı döviz kuru rejimine geçilmiştir. Bunun yanında, Ocak 2002'de dalgalı kur rejimi altında gelecek dönem enflasyonuna odaklanan, örtük enflasyon hedeflemesinin uygulanması yönünde karar alınmış, 2002 yılının ortasından itibaren hayata geçirilmiştir. Nitekim, dalgalı döviz kuru rejimi altında enflasyon hedeflemesinin oluşturduğu güven ortam1 2003 yılında döviz arz fazlasının yaşanmasına yol açmıştır.

2008 küresel kriz sonrasında ise, fiyat istikrarından ödün vermeden finansal istikrarı ön planda tutan para politikası stratejisi benimsenmiştir. Nisan 2010 'da, temel para politikası aracı olan 1 hafta vadeli repo ihale faiz oranıyla birlikte faiz koridoru ve zorunlu karşılıkların aktif olarak kullanılmasına karar verilmiştir. Ancak, likidite yönetiminde etkinliği artırmak için Eylül 2011'de döviz likiditesini doğrudan etkileyen rezerv opsiyon mekanizması (ROM) geliştirilmiştir. Bankaların, Türk lirası (TL) 
zorunlu karşılıklarının belirli bir yüzdesini döviz ve altın cinsinden tesis etmesine imkan veren ROM, 2012 yllından itibaren uygulamaya geçmiştir.

Birim kök testi sınamasından sonra LnSK serisinde ARCH etkisinin olup olmadığı test edilmiş ve sonuçları Tablo 4'te sunulmuştur. $L n S K$ serisinde güçlü bir ARCH etkisinin varlığı saptanmıştır.

Tablo 4: ARCH Etkisi Test Sonuçları

\begin{tabular}{lcc}
\hline Gecikme Sayısı & $\mathbf{N}^{*} \mathbf{R}^{\mathbf{2}}$ & $\boldsymbol{\chi}^{2}$-Olasılık \\
\hline 1 & 63.51609 & 0.0000 \\
\hline 5 & 26.59555 & 0.0001 \\
\hline 10 & 27.46545 & 0.0022 \\
\hline 15 & 35.17554 & 0.0023 \\
\hline
\end{tabular}

ARCH etkisi testi sonrasında, $L n S K$ serisinde otokorelasyonun varlığ Breusch-Goldfrey LM testiyle incelenmiştir. Tablo 5'te yer alan sonuçlara göre, otokorelasyon tespit edilen LnSK serisi otoregresif koşullu değişen varyans modellemelerine uygundur.

Tablo 5: Breusch-Goldfrey LM Testi Sonuçları

\begin{tabular}{lccc}
\hline F-İstatistiği & $\mathbf{N}^{*} \mathbf{R}^{\mathbf{2}}$ & F-Olasılık & $\boldsymbol{\chi}^{2}$-Olasıllık \\
\hline 41.11675 & 35.33608 & 0.0000 & 0.0000
\end{tabular}

ARCH etkisi ve Breush-Goldfrey testi sonuçları çerçevesinde, LnSK serisi volatilitesini açılayan en iyi GARCH modellemesinin tespitine geçilmiştir. Öncelikle simetrik GARCH, arkasindan asimetrik modeller olan EGARCH, TGARCH ve PARCH modelleri normal ve Student-t dağılımları altında tahmin edilmiştir. Söz konusu en iyi modelin seçiminde, parametrelerin istatistiksel bakımdan anlamlılığ 1 , varyans parametrelerinin yönü, maksimum log olabilirlik, minimum Akaike bilgi kriteri (AIC) ve Schwarz bilgi kriteri (SIC) kriterlerinin karşılaştırılması etkili olacaktır.

Sepet kura ilişkin GARCH $(1,1)$ modeli tahmin sonuçları Tablo 6'da sunulmuştur. Normal ve Student-t dağılımı modellemelerinde yer alan $\alpha_{1}$; sepet kura yönelik şokları, $\beta_{1}$; bir önceki döneme ilişkin sepet kur volatilitesinin cari dönem sepet kur volatilitesine etkisini temsil etmektedir. Her iki parametre toplamının 1'e yakın olması da sepet kurdaki volatilite dinamiklerinin direncini ifade etmektedir. Hem parametrelerin istatistiksel bakımdan anlamlılığ hem maksimum log olabilirlik, minimum AIC ve SIC kriterleri göz önünde bulundurulduğunda en iyi simetrik modeli Student-t dağılımı altındaki GARCH $(1,1)$ modeli karşılamaktadır.

Tablo 6: GARCH $(1,1)$ Modeli Tahmin Sonuçları

\begin{tabular}{|c|c|c|c|}
\hline & & Normal Dağılım & Sudent-t Dağılımı \\
\hline \multirow{2}{*}{$\begin{array}{l}\text { Ortalama Denklemi } \\
\operatorname{LnSK}_{t}=c+b_{1}+L n S K_{t-1}\end{array}$} & $c$ & $\begin{array}{c}0.0032 \\
(0.1950) \\
\end{array}$ & $\begin{array}{c}3.6305 \\
(0.9771) \\
\end{array}$ \\
\hline & $b_{1}$ & $\begin{array}{c}0.3179 \\
(0.0000) \\
\end{array}$ & $\begin{array}{r}0.2019 \\
(0.0000) \\
\end{array}$ \\
\hline \multirow{6}{*}{$\begin{array}{l}\text { Varyans Denklemi } \\
\sigma_{t}^{2}=c+\alpha_{1} \varepsilon_{t-1}^{2}+\beta_{1} \sigma_{t-1}^{2}\end{array}$} & $c$ & $\begin{array}{c}-0.0002 \\
(0.0270)^{* *}\end{array}$ & $\begin{array}{c}0.0004 \\
(0.0000)\end{array}$ \\
\hline & $\alpha_{1}$ & $\begin{array}{c}-0.2302 \\
(0.0138) * * *\end{array}$ & $\begin{array}{l}-1.2830 \\
(0.0000) \\
\end{array}$ \\
\hline & $\beta_{1}$ & $\begin{array}{c}0.4982 \\
(0.0022) \\
\end{array}$ & $\begin{array}{l}-0.0806 \\
(0.0006)\end{array}$ \\
\hline & Log Olabilirlik & 495.4769 & 511.6710 \\
\hline & AIC & -4.219628 & -4.350612 \\
\hline & SIC & -4.130489 & -4.246615 \\
\hline
\end{tabular}

Not: LnSK; sepet kurdur. Parantez içindeki değerler, olasılık değerleridir. ****** sırasıyla, \%1, \%5 anlamlılık düzeyidir.

Ancak, GARCH modeli sadece parametre büyüklüğünü dikkate alıp varyans dinamiklerini yakalarken, parametre işaretlerini göz ardı ettiği için şokların volatilite üzerindeki etkisini yakalayamamaktadır. Bu nedenle, varyans dinamiklerinde asimetrik volatilitenin varlığını test eden asimetrik GARCH modelleri uygulanmıştır. Asimetri etkisini belirlemeye yönelik ilk olarak EGARCH $(1,1)$ modeli tahmin sonuçlarına Tablo 7 'de yer verilmiştir. Parametrelerin istatistiksel bakımdan anlamlılığı, maksimum log olabilirlik ve minimum AIC ve SIC kriterleri en iyi asimetrik modelin Student-t dağılımı altındaki EGARCH $(1,1)$ modeli olduğunu belirtirken, asimetri etkisini temsil eden 
$\gamma_{1}$ parametresi her iki modelde pozitif ve istatistiksel bakımdan anlamlıdır. Bu durum, sepet kur volatilitesi üzerinde pozitif şokların negatif şoklara kıyasla daha etkili olduğunu göstermektedir. Diğer bir deyişle, sepet kurun değeri artarken, TL değer kaybetmektedir.

Tablo 7. EGARCH $(1,1)$ Modeli Tahmin Sonuçları

\begin{tabular}{|c|c|c|c|}
\hline & & Normal Dağılım & Sudent-t Dağılımı \\
\hline \multirow{2}{*}{$\begin{array}{l}\text { Ortalama Denklemi } \\
\operatorname{LnSK}_{t}=c+b_{1}+\operatorname{LnS} K_{t-1}\end{array}$} & $c$ & $\begin{array}{c}0.0055 \\
(0.0053)\end{array}$ & $\begin{array}{c}0.0037 \\
(0.0287)^{* *}\end{array}$ \\
\hline & $b_{1}$ & $\begin{array}{c}0.3842 \\
(0.0000)\end{array}$ & $\begin{array}{c}0.3641 \\
(0.0000)\end{array}$ \\
\hline \multirow{7}{*}{$\begin{array}{l}\text { Varyans Denklemi } \\
\log \left(\sigma_{t}^{2}\right)=c+\alpha_{1}\left|\frac{\varepsilon_{t-1}}{\sigma_{t-1}}\right|+ \\
\gamma_{1}\left|\frac{\varepsilon_{t-1}}{\sigma_{t-1}}\right|+\beta_{1} \log \left(\sigma_{t-1}^{2}\right)\end{array}$} & $c$ & $\begin{array}{l}-2.2623 \\
(0.0000)\end{array}$ & $\begin{array}{l}-2.6733 \\
(0.0002)\end{array}$ \\
\hline & $\alpha_{1}$ & $\begin{array}{c}0.2299 \\
(0.0145)^{* *}\end{array}$ & $\begin{array}{c}0.3733 \\
(0.0213) * *\end{array}$ \\
\hline & $\gamma_{1}$ & $\begin{array}{c}0.3967 \\
(0.0000) \\
\end{array}$ & $\begin{array}{c}0.3838 \\
(0.0007) \\
\end{array}$ \\
\hline & $\beta_{1}$ & $\begin{array}{c}0.7131 \\
(0.0000)\end{array}$ & $\begin{array}{c}0.6747 \\
(0.0000) \\
\end{array}$ \\
\hline & Log Olabilirlik & 507.5515 & 513.9358 \\
\hline & AIC & -4.315099 & -4.361515 \\
\hline & SIC & -4.211103 & -4.242662 \\
\hline
\end{tabular}

Not: LnSK; sepet kurdur. Parantez içindeki değerler, olasılık değerleridir. **, \%5 anlamlılık düzeyidir.

Tablo 8'de ise, EGARCH modeliyle benzer süreci paylaşan, ancak negatif asimetri etkisi parametresini baz alan TGARCH $(1,1)$ modeli tahmin sonuçlarına yer verilmiştir. Maksimum log olabilirlik, minimum AIC ve SIC kriterleri en iyi asimetrik modelin Student-t dağılımı altındaki TGARCH $(1,1)$ modeli olduğu belirtirken, $\beta_{1}$ parametresi dışında, parametrelerin istatistiksel bakımdan anlamlı olduğu, yalnız, bir önceki döneme ilişkin sepet kur volatilitesinin cari dönem sepet kur volatilitesini etkilemediği görülmektedir. Asimetri etkisini temsil eden $\gamma_{1}$ parametresi ise her iki modelde negatif ve istatistiksel bakımdan anlamlıdır.

Yalnız, EGARCH ve TGARCH modellerinde asimetri etkisi farkl1lık göstermektedir. Söz konusu parametre, EGARCH modelinde pozitif ve anlaml, TGARCH modelinde negatif ve anlamlı ise pozitif şoklar negatif şoklara kıyasla volatiliteyi daha fazla etkilemektedir. Bu kapsamda, TGARCH $(1,1)$ elde edilen sonuçlar, EGARCH $(1,1)$ modeliyle uyumluyken; sepet kurun değeri artarken, TL değer kaybetmektedir.

Tablo 8. TGARCH $(1,1)$ Modeli Tahmin Sonuçları

\begin{tabular}{|c|c|c|c|}
\hline & & Normal Dağılım & Sudent-t Dağılımı \\
\hline \multirow{2}{*}{$\begin{array}{l}\text { Ortalama Denklemi } \\
\operatorname{LnSK}_{t}=c+b_{1}+\operatorname{LnS} K_{t-1}\end{array}$} & $c$ & $\begin{array}{c}0.0039 \\
(0.0740)^{*} \\
\end{array}$ & $\begin{array}{c}0.0034 \\
(0.0369)^{* *} \\
\end{array}$ \\
\hline & $b_{1}$ & $\begin{array}{c}0.3563 \\
(0.0000) \\
\end{array}$ & $\begin{array}{c}0.3296 \\
(0.0000) \\
\end{array}$ \\
\hline \multirow{7}{*}{$\begin{array}{l}\text { Varyans Denklemi } \\
\sigma_{t}^{2}=c+\alpha_{1} \varepsilon_{t-1}^{2}+\gamma_{1} \varepsilon_{t-1}^{2}\left(\varepsilon_{t-1}<\right. \\
0)+\beta_{1} \sigma_{t-1}^{2}\end{array}$} & $c$ & $\begin{array}{c}0.0003 \\
(0.0001) \\
\end{array}$ & $\begin{array}{c}0.0003 \\
(0.0003) \\
\end{array}$ \\
\hline & $\alpha_{1}$ & $\begin{array}{c}0.7792 \\
(0.0015) \\
\end{array}$ & $\begin{array}{c}1.0554 \\
(0.0120)^{* * *} \\
\end{array}$ \\
\hline & $\gamma_{1}$ & $\begin{array}{l}-0.8327 \\
(0.0009) \\
\end{array}$ & $\begin{array}{c}-0.0067 \\
(0.0154)^{* *}\end{array}$ \\
\hline & $\beta_{1}$ & $\begin{array}{l}0.2649 \\
(0.0387)^{* *}\end{array}$ & $\begin{array}{c}0.1441 \\
(0.3085) \\
\end{array}$ \\
\hline & Log Olabilirlik & 505.0788 & 515.9347 \\
\hline & AIC & -4.293783 & -4.378748 \\
\hline & SIC & -4.189787 & --4.259894 \\
\hline
\end{tabular}

Not: LnSK; sepet kurdur. Parantez içindeki değerler, olasılık değerleridir. Parantez içindeki değerler, olasılık değerleridir. ***, **, * sırasıyla, $\% 1, \% 5$ ve $\% 10$ anlamlılık düzeyidir.

Son olarak, asimetri etkisinin yanında volatilitenin zamana bağlılığını da ölçen PARCH $(1,1)$ modeli tahmin sonuçları Tablo 9'da sunulmuştur. Parametrelerin istatistiksel bakımdan anlamlılığı maksimum log olabilirlik ve minimum AIC ve SIC kriterleri en iyi asimetrik modelin Student-t dağılımı altındaki PARCH $(1,1)$ modeli olduğunu belirtirken, asimetri etkisini temsil eden $\gamma_{1}$ parametresi her iki modelde negatif ve istatistiksel bakımdan anlamlıdır. Elde edilen sonuçlar, 
TGARCH $(1,1)$ uyumludur. Ayrıca, PARCH $(1,1)$ modelinde standart sapmanın kuvvet parametresini temsil eden $\delta$ değerlendirilmiştir. $\delta$ 'nin sıfirdan büyük ve anlamlı olması, sepet kurun zamana bağlı volatilitesinin yüksek olduğuna işaret etmektedir.

Tablo 9. PARCH $(1,1)$ Modeli Tahmin Sonuçları

\begin{tabular}{|c|c|c|c|}
\hline & & Normal Dağılım & Sudent-t Dağılımı \\
\hline \multirow{2}{*}{$\begin{array}{l}\text { Ortalama Denklemi } \\
L n S K_{t}=c+b_{1}+\operatorname{LnS} K_{t-1}\end{array}$} & $c$ & $\begin{array}{c}0.0059 \\
(0.0025)\end{array}$ & $\begin{array}{c}0.0038 \\
(0.0206)^{* *}\end{array}$ \\
\hline & $b_{1}$ & $\begin{array}{c}0.3554 \\
(0.0000)\end{array}$ & $\begin{array}{c}0.3404 \\
(0.0000)\end{array}$ \\
\hline \multirow{8}{*}{$\begin{array}{l}\text { Varyans Denklemi } \\
\sigma_{t}^{2}=c+\left(\alpha_{1}\left|\varepsilon_{t-1}\right| \gamma_{1} \varepsilon_{t-1}\right)^{\delta}+ \\
\beta_{1} \sigma_{t-1}^{\delta}\end{array}$} & $c$ & $\begin{array}{c}0.0551 \\
(0.1974)\end{array}$ & $\begin{array}{c}0.0253 \\
(0.5021)\end{array}$ \\
\hline & $\alpha_{1}$ & $\begin{array}{c}0.1839 \\
(0.0002) \\
\end{array}$ & $\begin{array}{c}0.2819 \\
(0.0059)^{* * *}\end{array}$ \\
\hline & $\gamma_{1}$ & $\begin{array}{l}-0.9989 \\
(0.0000)\end{array}$ & $\begin{array}{l}-0.8740 \\
(0.0013)\end{array}$ \\
\hline & $\delta$ & $\begin{array}{c}0.5079 \\
(0.0138)^{* * *}\end{array}$ & $\begin{array}{c}0.7635 \\
(0.0587)^{*}\end{array}$ \\
\hline & $\beta_{1}$ & $\begin{array}{c}0.5506 \\
(0.0000) \\
\end{array}$ & $\begin{array}{c}0.4010 \\
(0.0075)\end{array}$ \\
\hline & Log Olabilirlik & 511.0333 & 516.8064 \\
\hline & AIC & -4.336494 & -4.377642 \\
\hline & SIC & -4.217641 & -4.243932 \\
\hline
\end{tabular}

Not: LnSK; sepet kurdur. Parantez içindeki değerler, olasılık değerleridir. ***,**, * sırasıyla, $\% 1, \% 5$ ve $\% 10$ anlamlılık düzeyidir.

Genel bir değerlendirme yapıldığında, tahmin edilen tüm GARCH modellerinin Student-t dağılımı altında en iyi sonucu verdiği saptanmıştır. Söz konusu modeller içerisinde ise en iyi modeli saptamak için modellerin maksimum log olabilirlik, minimum AIC ve SIC karşılaştırması yapılmıştır.

Tablo 10'da yer verilen sonuçlara göre, sepet kur volatilitesinin açıklanmasında en iyi model PARCH $(1,1)$ modelidir. Student-t dağılımı altında PARCH $(1,1)$ modelinin öngörü performansı da incelenmiştir.

Tablo 10: GARCH Modellerinin Karşılaştırılması

\begin{tabular}{lcccc}
\hline & GARCH (1,1) & EGARCH (1,1) & TGARCH (1,1) & PARCH (1,1) \\
\hline Log Olabilirlik & 511.6710 & 513.9358 & 515.9347 & 516.8064 \\
\hline AIC & -4.350612 & -4.361515 & -4.378748 & -4.377642 \\
\hline SIC & -4.246615 & -4.242662 & -4.259894 & -4.243932 \\
\hline
\end{tabular}

Dinamik ve statik öngörü istatistiklerine ilişkin hata kareler ortalamasının karekökü (Root Mean Squared Error: RMSE) ve hatanın mutlak ortalaması (Mean Absolute Error: MAE) kriterlerinin baz alındığı sonuçlar Tablo 11'de yer almıştır. Dinamik ve statik öngörü sonuçları incelendiğinde, RMSE ve MAE değerlerinin sıfira yakın olduğu görülmektedir. Buna göre, Student-t dağılımı altındaki PARCH $(1,1)$ modeli, $L n S K$ serisinin geleceğe yönelik projeksiyonunda başarılıdır.

Tablo 11: Student- t Dağılımı PARCH $(1,1)$ Modeli Öngörü Sonuçları

\begin{tabular}{lcc}
\hline & Dinamik Öngörü & Statik Öngörü \\
\hline RMSE & 0.0362 & 0.0339 \\
\hline MAE & 0.0240 & 0.0228 \\
\hline
\end{tabular}

\section{SONUÇ}

Döviz kuru volatilitesi modellemeleri, finansal risk ölçümü konusunda politika yapıcılar ve ekonomistler için yol göstericidir. Gerek politika yapıcılar gerekse piyasa katılımcıları için ekonomik faaliyetlerin seyri, varlık değerlemesi ve portföy seçimine ilişkin risk yönetimi ve savunması konusunda belirleyicidir.

Bu çalışmada, asimetri etkisi kapsamında Türkiye'de sepet kur volatilitesi 2001:M1-2020:M6 döneminde GARCH modeliyle analiz edilmiştir. İlk aşamada, birim kök testi sınamalarının ardından sepet kur serisinde ARCH etkisinin varlığı tespit edilmiş, otoregresif değişen varyans modellerine uygunluğu Breusch-Goldfrey LM testiyle saptanmıştır. İkinci aşamada, simetrik GARCH, arkasından asimetrik modeller olan EGARCH, TGARCH ve PARCH modelleri normal ve Student-t dağılımları 
altında tahmin edilmiştir. Söz konusu modeller arasından en iyi modelin seçiminde, parametrelerin istatistiksel bakımdan anlamlılığı, varyans parametrelerinin yönü, maksimum log olabilirlik, minimum AIC ve SIC kriterleri karşılaştırılmıştır. Buna göre, sepet kur volatilitesinin açıklanmasında en iyi model olarak PARCH $(1,1)$ modeli belirlenmiştir. Son aşamada ise, Student-t dağılımı altında PARCH $(1,1)$ modelinin öngörü performans1, dinamik ve statik öngörü RMSE ve MAE kriterlerine göre değerlendirilmiştir. Sonuç olarak, Student-t dağılımı altındaki PARCH $(1,1)$ modelinin, sepet kurun geleceğe yönelik projeksiyonlarında başarılı olduğu görülmüştür. Elde edilen bulgular, Korur (2019) ve Ilu (2020) çalışmalarıyla uyumludur.

Asimetrik GARCH modellerinden elde edilen bulgular, sepet kurun izlediği ve izleyeceği seyir hakkında kötü habere işaret etmektedir. EGARCH $(1,1)$ modelinde pozitif ve anlamlı, TGARCH $(1,1)$ modelinde negatif ve anlamlı ise pozitif şoklar negatif şoklara kıyasla volatiliteyi daha fazla etkilemekte yani sepet kurun değeri artarken, TL değer kaybetmektedir.

Diğer taraftan, PARCH $(1,1)$ modelinden elde edilen bulgulara göre, sepet kurun zamana bağl1 volatilitesinin yüksektir ve süreklilik bakımından direnç göstermektedir. Türkiye ekonomisiyle uyumlu olan bulgular, ilgili dönem ele alındığında, Kasım 2000 ve Şubat 2001 krizleri sonrasında, uygulanan dalgalı döviz kuru rejimi altında enflasyon hedeflemesi ile 2008 küresel krizinden sonra doğrudan döviz likiditesini etkilemeyi amaçlayan yeni para politikası aracı ROM, küresel reel sektör ve finansal piyasalardaki konjonktür, komşu ülkelerde yaşanan siyasi ve sosyo-ekonomik gelişmeler karşısında ekonomik birimlerin beklentilerindeki ani değişimler sonucu aldıkları kararlar sepet kur şoklarını açıklamaktadır.

Volatilite olarak nitelendirilen, döviz kurundaki hılı yükseliş ve düşüş yönlü dalgalanmalar, üretim, yatırım, tasarruf, fiyatlama, dış ticaret, yabancı sermaye ve beklentiler gibi ekonomik faaliyetlerin istikrarlı bir zeminde oluşmasını engellemektedir. Çünkü döviz kurunda birbirini kısır döngü şeklinde izleyen hızlı yükseliş ve düşüşler sonrasında, ekonomide yaşanan dengesizlik kısa dönemde giderilememektedir. Dolayısıyla, döviz kuru volatilitesinin öngörülmesi de alınacak ekonomik önlemler açısından önem arz etmektedir. Küresel ekonomik faaliyetlerin izlediği seyre göre şekillenen enflasyonist beklentiler, gelişmiş ülke merkez bankalarının uyguladığı para politikaları sonucu gelişmekte olan ülkelere yönelik finansal varlık talebi ve risk iştahındaki değişim, döviz kuru volatilitesinin öngörülmesinde temel göstergelerdir. Ayrıca, ülkelerin dışa açıklık derecesine bağlı olarak, dış ticarette korumacılık önlemleri ve ticaret savaşları da döviz kuru volatilitesinin öngörülmesi yönünde etkili olmaktadır.

Etik Beyan: Bu çalışmada "Etik Kurul” izini alınmasını gerektiren bir yöntem kullanılmamıştır.

Ethics Statement: In this study, no method requiring the permission of the "Ethics Committe" was used.

\section{KAYNAKÇA}

Abdullah, S. M., Siddiqua, S., Siddiquee, M. S. H., \& Hossain, N. (2017). Modeling and forecasting exchange rate volatility in Bangladesh using GARCH models: A comparison based on normal and student's t-error distribution. Financial Innovation, 3(18), 1-19. https://doi.org/10.1186/s40854-017-0071-z

Adeoye, B. W., \& Atanda, A. A. (2011). Exchange rate volatility in Nigeria: Consistency, persistency \& severity analyses. CBN Journal of Applied Statistics, 2(2), 29-49. http://hdl.handle.net/10419/142049

Andersen, T. G., \& Bollerslev, T. (1997). Intraday periodicity and volatility persistence in financial markets. Journal of Empirical Finance, 4, 115-158. https://doi.org/10.1016/S09275398(97)00004-2

Baillie, R. T., \& Bollerslev, T. (1989). The message in daily exchange rates: A conditional variance tale. Journal of Business and Economic Statistics, 7(3), 297-305. https://EconPapers.repec.org/RePEc:bes:jnlbes:v:7:y:1989:i:3:p:297-305 
Bala, D. A., \& Asemota, J. O. (2013). Exchange-rates volatility in Nigeria: Application of GARCH models with exogenous break. CBN Journal of Applied Statistics, 4(1), 89-116. http://hdl.handle.net/10419/142075

Bollerslev, T. (1986). Generalized autoregressive conditional heteroscedasticity. Journal of Econometrics, 31(3), 307-327. https://doi.org/10.1016/0304-4076(86)90063-1

Bordo, M. D., \& Meissner, C. M. (2015). Fiscal and financial crises. Handbook of Macroeconomics, 2, 1-94. https://doi: 10.1016/bs.hesmac.2016.04.001

Bosnjak, M., Novak, I., \& Bilas, V. (2016). Modelling volatility of exchange rate currency using GARCH models. Economski Vjesnik/ Econviews, 29(1) 81-94. https://hrcak.srce.hr/ojs/index.php/ekonomski-vjesnik/issue/view/164

Diebold, F. X. (1988). Empirical modeling of exchange rate dynamics. Springer-Verlag.

Ding, Z., Granger, W. J., \& Engle, R. F. (1993). A long memory property of stock market returns and a new model. Journal of Empirical Finance, 1(1), 83-106. https://doi.org/10.1016/09275398(93)90006-D.

Domowitz, I., \& Hakkio, C. S. (1985). Conditional variance and the risk premium in the foreign exchange market. Journal of International Economics, 19(1-2), 47-66. https://doi.org/10.1016/0022-1996(85)90018-2

Dursun, G. (2015). Türkiye'de reel döviz kuru belirsizliği ve yurtiçi yatırımlar. Eskişehir Osmangazi $\begin{array}{llll}\text { Universitesi } & \text { IIBF } & \text { Dergisi, } & \text { 10(1), }\end{array}$ https://dergipark.org.tr/tr/pub/oguiibf/issue/56487/785411

Emeç, H., \& Özdemir, M. O. (2014). Türkiye'de döviz kuru oynaklığının otoregresif koşullu değişen varyans modelleri ile incelenmesi. Finans Politik \& Ekonomik Yorumlar, 51(596), 85-99. https://www.researchgate.net/publication/298789240

Engle, R. F. (1982). Autoregressive conditional heteroscedasticity with estimates of the variance of U.K. inflation. Econometrica, 50(4), 987-1008. http://www.econ.uiuc.edu/ econ536/Papers/engle82.pdf

Engle, R. F., \& Bollerslev, T. (1986). Modelling the persistence of conditional variances. Econometric Reviews, 5(1), 1-50. https://doi.org/10.1080/07474938608800095

Epaphra, M. (2017). Modeling exchange rate volatility: Application of the GARCH and EGARCH models. Journal of Mathematical Finance, 7(1), 121-143. https://doi: 10.4236/jmf.2017.71007

Gabaix, X., \& Maggiori, M. (2015). International liquidity and exchange rate dynamics. The Quarterly Journal of Economics, 130(3), 1369-1420. RePEc:oup:qjecon:v:130:y:2015:i:3:p:1369-1420.

Güloğlu, B., \& Akman, A. (2007). Türkiye'de döviz kuru oynaklığının SWARCH yöntemi ile analizi. Finans Politik \& Ekonomik Yorumlar, 44(512), 44-51. https://www.researchgate.net/publication/298789240_Turkiye'de_Doviz_Kuru_Oynakliginin_O toregresif_Kosullu_Degisen_Varyans_Modelleri_ile_Incelenmesi

Gür, T. H., \& Ertuğrul, H. M. (2012). Döviz kuru volatilitesi modelleri: Türkiye uygulaması. İktisat Issletme ve Finans, 27(310), 53-77. https://doi: 10.3848/iif.2012.310.3197

Güvenek, B., \& Alptekin, V. (2009). Reel döviz kuru endeksinin otoregresif koşullu değişen varyanslılığının analizi: İki eşikli TARCH yöntemi ile modellenmesi. Maliye Dergisi, 156, 294310. https://ms.hmb.gov.tr/uploads/2019/09/18.Burcu_GuVENEK_Volkan.ALPTEKiN.pdf

Hsieh, D. A. (1989). Modeling heteroscedasticity in daily foreign-exchange rates. Journal of Business $\begin{array}{llll}\text { and Economic } & \text { Statistics, } & \text { 307-317. }\end{array}$ https://EconPapers.repec.org/RePEc:bes:jnlbes:v:7:y:1989:i:3:p:307-17 
Ilu, A. I. (2020). Exchange rate pass through to stock prices: A multi GARCH approach. Munich Personal RePEc Archive, 98442, 1-20. https://mpra.ub.unimuenchen.de/98442/1/MPRA paper 98442.pdf

İşçioğlu, F., \& Gülay, E. (2018). ABD doları/Türk lirası döviz kurunun otoregresif koşullu değişen varyans modelleri ile incelenmesi: Türkiye örneği. Uluslararası İktisadi ve İdari İncelemeler Dergisi, 2018(20), 151-168. https://doi.org/10.18092/ulikidince.338893

Kaplan, F. (2009). Türkiye'de reel döviz kurlarındaki oynaklık issizlik ve büyüme oranları üzerine etkileri (Yayın no 239708) [Yüksek Lisans Tezi, Isparta Süleyman Demirel Üniversitesi Sosyal Bilimler Enstitüsü]. Yüksek Öğretim Kurumu Tez Merkezi. https://tez.yok.gov.tr/UlusalTezMerkezi/tezSorguSonucYeni.jsp

Kayral, İ. E. (2016). Türkiye'de döviz kuru volatilitelerinin modellenmesi. Politik Ekonomik ve Finansal Analiz Dergisi, $1(1), \quad$ 1-15. https://papers.ssrn.com/sol3/papers.cfm?abstract_id=2882895

Koop, G., \& Korobilis, D. (2014). A new index of ginancial conditions. European Economic Review, 71, 101-116. https://doi: 10.1016/j.euroecorev.2014.07.002

Korur, S. (2019). Döviz kuru dalgalanmalarının öngörülmesi ve hedging (risk yönetimi) (Yayın no) 562425) [Yüksek Lisans Tezi, Ankara Hacettepe Üniversitesi Sosyal Bilimler Enstitüsü]. Yüksek Öğretim Kurumu Tez https://tez.yok.gov.tr/UlusalTezMerkezi/tezSorguSonucYeni.jsp

May, C., \& Farrell, G. (2017). Modelling exchange rate volatility dynamics: Empirical evidence from South Africa. ERSA Working Paper, 705, https://www.econrsa.org/system/files/publications/working_papers/working_paper_705.pdf

Milhoj, A. (1987). A conditional variance model for daily observations of an exchange rate. Journal of Business and Economic Statistics, 5(1), 99-103. https://doi.org/10.2307/1391219

Mohsin, M. (2018). Modelling exchange rate volatility using GARCH models: Empirical evidence from Pakistan. European Journal of Research, 1(2), 73-88. https://doi: 10.26739/2521-3253

Nelson, D. B. (1991). Conditional heteroscedasticity in ssset returns: A new approach. Econometrica, 59(2), 347-370. https://doi.org/10.2307/2938260

Parim, C. (2014). Türkiye'deki dolar kuru volatilitesinin modellenmesi (Yayın no 372478) [Yüksek Lisans Tezi, İstanbul Üniversitesi]. Yüksek Öğretim Kurumu Tez Merkezi. https://tez.yok.gov.tr/UlusalTezMerkezi/tezSorguSonucYeni.jsp

Petrica, A. C., \& Stancu, S. (2017). Empirical results of modeling EUR/RON exchange rate using ARCH, GARCH, EGARCH, TARCH and PARCH models. Romanian Statistical Review, 65(1), 57-72. RePEc:rsr:journl:v:65:y:2017:i:1:p:57-72

Rabemananjara, R., \& Zakoian, J. M. (1993). Threshold ARCH models and asymmetries in volatility. Journal of Applied Econometrics, 8, 31-49. https://doi.org/10.1002/jae.3950080104

Sağlam, M., \& Başar, M. (2016). Döviz kuru oynaklığının öngörülmesi: Türkiye örneği. KMÜ Sosyal $\begin{array}{llll}\text { ve Ekonomik Araştırmalar } & \text { 23-29. }\end{array}$ http://dergi.kmu.edu.tr/userfiles/files/2016Aral\%C4\%B1k/3M_\%20Sa\%C4\%9Flam\%2C\%20M_\%20Ba\%C5\%9Far_D\%C3\%B6viz\%20Kuru\%20Oynakl\% C4\%B1\%C4\%9F\%C4\%B1n\%C4\%B1n.pdf

Schwert, G. W. (1990). Stock volatility and the crash of' 87. Review of Financial Studies, 3(1), 77102. https://EconPapers.repec.org/RePEc:oup:rfinst:v:3:y:1990:i:1:p:77-102

Sekmen, F., \& Ravanoğlu, G.A. (2020). The modelling of exchange rate volatility using ARCHGARCH models: The case of Turkey. MANAS Sosyal Araştırmalar Dergisi, 9(2), 835-843. https://doi.org/10.33206/mjss.541309 
Songül, H. (2015). Otoregresif koşullu değişen varyans modelleri: Döviz kurlarl üzerine uygulama [Uzmanlık Tezi, Türkiye Cumhuriyet Merkez Bankas1]. http://www3.tcmb.gov.tr/kutuphane/TURKCE/tezler/huseyinsongul.pdf

Soytaş, U., \& Ünal, S. (2010). Türkiye döviz piyasalarında oynaklığın öngörülmesi ve risk yönetimi kapsamında değerlendirilmesi. Yönetim ve Ekonomi, 17(1), 122-146. https://dergipark.org.tr/tr/download/article-file/146034

Taylor, S. J. (1986). Modelling financial time series. John Wiley \& Sons.

Tetik, N., \& Kanat, E. (2016). Döviz kuru riskinin ölçülmesinde GARCH yönteminin uygulanması. Sosyal ve Beşeri Bilimler Araştırmaları Dergisi, 17(37), 122-139. https://dergipark.org.tr/tr/pub/sobbiad/issue/36438/413029

Topaloğlu, T. N., \& Ünal, A. (2019). Döviz kuru getiri volatilitesinin modellenmesi: Dolar ve Euro serileri üzerine bir uygulama. MANAS Sosyal Araştırmalar Dergisi, 8(4), 3352-3378 https://doi.org/10.33206/mjss.502308

Türkiye Cumhuriyet Merkez Bankası (Temmuz, 2020). Döviz kurları. Elektronik Veri Dağıtım Sistemi. http://evds.tcmb.gov.tr

Uysal, D., \& Özşahin, Ş. (2012). Reel efektif döviz kuru endeksi volatilitesinin ARCH ve GARCH modelleri ile tahmini. Anadolu Üniversitesi Sosyal Bilimler Dergisi, 1(12), 13-20. https://kutuphane.dogus.edu.tr/mvt/pdf.php?lng=1\&search=\&articlelng=\&fieldnu=0\&sortnu=0 $\underline{\text { sortdir }=0 \& \text { access }=\text { catalog } \& p d f=0012086 \& \text { journalbg }=* \&-\max =20 \& \text {-skip }=0}$

Yang, L. (2006). A semiparametric GARCH model for foreing exchange rate. Journal of Econometrics, 130(2), 365-384. https://doi: 10.1016/j.jeconom.2005.03.006 